\title{
Cutaneous Anthrax Patients: Evaluation of Four Family Members
}

\author{
Kamil Tünay ${ }^{1}$, Havva Tünay ${ }^{2}$, Neşe Demirtürk², Oya Oruç ${ }^{1}$, Talip Çevik' ${ }^{1}$, Ahmet Boyacl ${ }^{3}$ \\ 'Department of Emergency Medicine, Afyonkocatepe Universty School of Medicine, Afyonkarahisar, Turkey \\ 2Departments of Infectious Disease and Clinical Microbiology, Afyonkocatepe Universty School of Medicine, Afyonkarahisar, Turkey \\ ${ }^{3}$ Departments of Infectious Disease and Clinical Microbiology, Afyonkocatepe State Hospital, Afyonkarahisar, Turkey
}

\begin{abstract}
Anthrax is a zoonotic infectious disease caused by B.anthracis. Declining with each passing day in our country is still an endemic disease. Cutaneous anthrax(CA) is the most common form and consists of approximately $95 \%$ of all cases of anthrax. In this study, we report and discuss with literature 4 skin anthrax diagnosed patients who admitted to emergency service with complaints of no pain and black colored wound on their hands in the same family members. (Eurasian J Emerg Med 2016; 15:54-5)
\end{abstract}

Keywords: Anthrax, cutaneous anthrax, bacillus anthracis

\section{Introduction}

Anthrax is a zoonotic and sometimes fatal infectious disease caused by Bacillus anthracis. Contamination occurs when endospores enter the body through skin abrasions, inhalation, or ingestion. Humans are considered as an incidental host and acquire the infection by direct or indirect contact or from animal products (1). Anthrax in humans may present itself in four different clinical pictures: cutaneous, inhalational, gastrointestinal, and oropharyngeal. Infection in humans most often involves the skin, causing cutaneous anthrax (CA), which comprises $95 \%$ of all anthrax cases. It mostly affects the hands, arms, face, and neck $(1,2)$.

A typical history that should raise suspicion for anthrax is a rapidly forming painless ulcer at the center of an edematous region following exposure. Anthrax still remains as an endemic zoonotic disease in Turkey. In this study, 4 family members who presented to the emergency department with painless and black anthrax lesions on their hands 1 week after cutting cattle are presented with a review of related literature.

\section{Case Presentation}

Four females from the same family were admitted to the emergency department with a complaint of lesions on their hands and fingers. Obtained their detailed history revealed that they cut cattle 1 week before admission. The appearance of cutaneous lesions was typical of CA (Figure 1). The patients were hospitalized in the Department of Infectious Diseases with the diagnosis of anthrax. On their initial physical examination, they were afebrile and all vital signs were found to be normal. The examination of other organ systems revealed nothing pathological. Blood samples were taken for routine analysis. Table 1 shows demographic features and laboratory results of the patients. Penicillin G 800,000 IU $2 \times 1$ iv was commenced in all patients, which resulted in successful resolution of the skin lesions within 10 days.

\section{Discussion}

B. anthracis is a disease commonly occurring in tropical regions such as Africa, Asia, and South and Central America (3). In Turkey, although its incidence has been decreasing, it still remains as an endemic problem. In total, 10724 new human anthrax cases were reported between 1960 and 1969. The numbers of reported cases were as follows: 4423 cases between 1980 and 1989, 4220 cases between 1990 and 1999, and 2210 cases between 2000 and 2005. The Turkish Ministry of Health reported the number of new cases as 262,126 , and 132 in 2007, 2008, and 2009, respectively. This downward trend in the incidence of the disease might be due to developments in the economy and social areas, effective animal vaccination programs, and education programs involving farmers $(4,5)$.

Correspondence to: Kamil Tünay e-mail: kamiltunay@yahoo.com.tr

Received: 09.07.2015 Accepted: 27.10.2015

(C) Copyright 2016 by Emergency Physicians Association of Turkey - Available online at www.eajem.com

DOI: 10.5152/eajem.2016.80388 


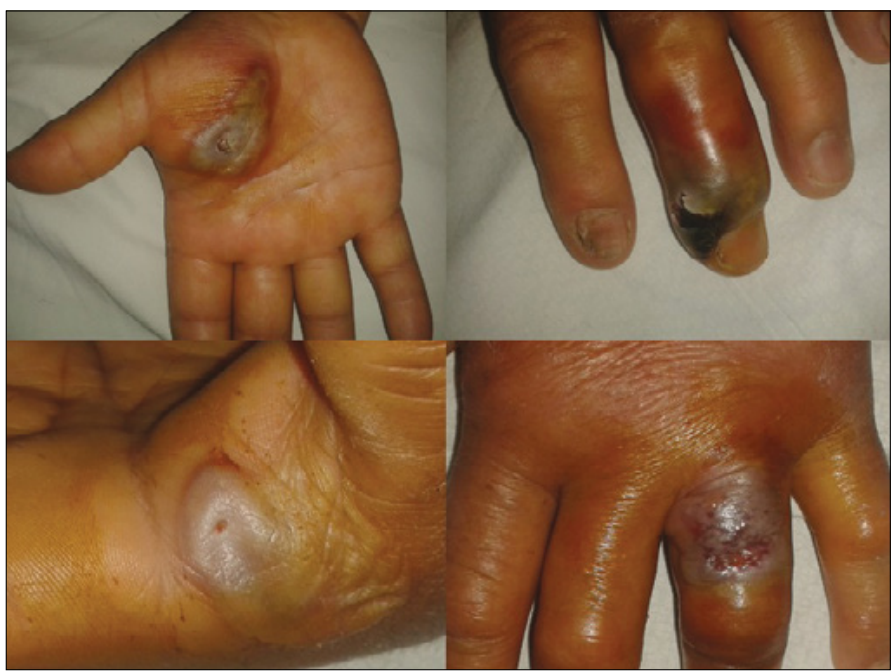

Figure 1. Cutaneous anthrax skin lesion in four family members

Table 1. Demographic and laboratory findings

\begin{tabular}{|l|c|c|c|c|}
\hline Patient number & $\mathbf{1}$ & $\mathbf{2}$ & $\mathbf{3}$ & $\mathbf{4}$ \\
\hline Age & 32 & 52 & 65 & 73 \\
\hline Gender & Female & Female & Female & Female \\
\hline WBC count & 12,290 & 9,970 & 13,030 & 5,460 \\
\hline Neutrophil (\%) & 74.2 & 74.7 & 78.2 & 75.8 \\
\hline CRP (mg/L) & 7.7 & 2.4 & 0.7 & 1.8 \\
\hline
\end{tabular}

WBC: white blood cell, CRP: C-reactive protein

B. anthracis is a gram-positive, aerobic or facultatively anaerobic, spore-forming, rod-shaped bacterium causing the clinical picture of anthrax. Because anthrax endospores may cease to grow, do not divide, and have no measurable metabolism, they are very resistant to harsh environmental conditions such as drying, heat, ultraviolet light, gamma radiation, and the application of many disinfectants (Dixon). Three types of proteins are present in anthrax toxin: protective antigen, edema factor, and lethal factor. These toxins cause toxic clinical manifestations by inhibiting the action of polymorphonuclear cells (6).

After acquiring CA infection, the clinical picture usually develops following an incubation period of 2-7 days, while it is known that clinical manifestations may be seen anytime between $9 \mathrm{~h}$ and 8 weeks after infection (7).

After receiving endospores, skin lesions develop within 3-5 days, and they are usually in the form of nondescript, painless, pruritic papules. Within 24-36 h, the lesion turns to a vesicle with central necrosis and drying, forming the unique black eschar surrounded by edema and few purplish vesicles. Malignant pustules, as common lesions, are not purulent and characteristically painless (1). The most common areas affected by lesions have been reported to be the hands, fingers, and arms, which are exposed to infected animal and animal products $(8,9)$. Our patients had malignant pustule lesions on their hands and fingers.

The disease mostly affects individuals who work in the fields of animal husbandry and agriculture. Patients working in the field of agriculture comprise most cases in developing countries as it occurs in Turkey. Some studies have reported farmers and housewives as high-risk occupations for the disease $(8,9)$. All patients in our study were female housewives.

Suspicion is the first step in CA diagnosis. In areas where the disease is not endemic, making the diagnosis may be rather difficult. Brown recluse spider bites, ecthyma, accidental vaccine, ulceroglandular tularemia, and necrotic herpes simplex should be considered in the differential diagnosis of CA. Making the diagnosis may be easier when a typical malignant pustule or extensive edema is present in a patient with a history of contact with animals $(5,8,9)$. All patients in our study had a history of direct or indirect contact by infected animals or animal products and lesions typical of the disease.

Penicillin G, an old drug, is still the first choice in treatment; doxycycline or ciprofloxacin are the best alternative options in the treatment of naturally occurring anthrax. Intravenous treatment is required in case of CA with systemic involvement and extensive edema (1). All patients in the present study received penicillin $\mathrm{G}$ for treatment. None of our patients developed complications such as secondary infection and toxemic shock, and no mortality occurred.

\section{Conclusion}

In conclusion, CA is an infectious disease and is an important cause of morbidity in Turkey. The prognosis is significantly affected by the time and accuracy of the diagnosis. In patients with suspicious skin lesions and a history of contact with animals or animal products, a diagnosis of CA should be considered.

Informed Consent: Written informed consent was obtained from patients who participated in this case.

Peer-review: Externally peer-reviewed.

Conflict of Interest: No conflict of interest was declared by the authors.

Financial Disclosure: The authors declared that this study has received no financial support.

\section{References}

1. Dixon TC, Meselson M, Guillemin J, Hanna PC. Anthrax. N Engl J Med 1999; 341: 815-26. [CrossRef]

2. Taş A, Yağız R, Gürcan Ş, Karaoğlu D. Oropharyngeal Anthrax. Turk J Med Sci 2008; 38: 621-3.

3. Jernigan JA, Stephans DS, Ashford DA, Omenaca C, Topiel MS, Galbraith $M$, et al. Bioterrorism-related inhalation anthrax: the first 10 cases reported in the United States. Emerg Infect Dis 2001; 7: 933-44. [CrossRef]

4. Özden K, Özkurt Z, Erol S, Uyanık MH, Parlak M. Cutaneous anthrax patients in Eastern Anatolia, Turkey: a review of 44 adults cases. Turk J Med Sci 2012; 42: 39-45.

5. Ozkurt Z, Parlak M, Tastan R, Dinler U, Sağlam YS, Ozyurek SF. Anthax in eastern Turkey, 1992-2004. Emerg Infect Dis 2005; 11: 1939-41. [CrossRef]

6. Babamahmoodi F, Aghabarari F, Arjmand A, Ashrafi GH. Three cases of anthrax arising from the same source. J Infect 2006; 53: 175-9. [CrossRef]

7. Tutrone WD, Scheinfeld NS, Weinberg JM. Cutaneous anthrax: A Concise Review Cutis 2001; 67: 491.

8. Engin A, Elaldi N, Dokmetas I, Bakici MZ, Kaya S, Bakir M. Cutaneous anthrax in the central Anatolia Region of Turkey: A review of 39 adults cases. Turkiye Klinikleri J Med Sci 2010; 30: 1032-8. [CrossRef]

9. Baykam N, Ergonul O, Ulu A, Eren S, Celikbas A, Eroglu M, et al. Characteristics of cutaneous anthrax in Turkey. J Infect Dev Ctries 2009; 3: 599-603. [CrossRef] 